\title{
COMPETITIVE INTELLIGENCE AND PRODUCT DEVELOPMENT / INNOVATIONS IN PHARMACEUTICAL FIRMS IN LAGOS STATE, NIGERIA
}

\author{
Nduka Kenneth Omede ${ }^{1}$ \\ Email: omesco63@gmail.com \\ Amaechi Sylvester Egwuenu \\ Ezem Matthew Ibekwe ${ }^{3}$
}

\begin{abstract}
This study examined competitive intelligence and product development and innovation in pharmaceutical firms in Lagos State, Nigeria. Three hypotheses were formulated to determine whether or not a relationship exist between competitive intelligence and product development and innovation in pharmaceutical firms in Lagos State, Nigeria. The study adopted a survey research design to obtain data, using a structured questionnaire which was analyzed using Pearson's product moment coefficient of correlation. The result indicated that there exists a significant relationship between competitive intelligence and product development and innovation in pharmaceutical firms in Lagos State, Nigeria. Based on the finding it was concluded that the process of product development and innovation cannot be successful except there is information about customer's needs, wants and expectations of which the innovation products or services intends to serve. The study recommended among others that pharmaceutical firms should leverage on information gathering and sharing to determine the nature of the new product and service so that the new product offerings will be more valued and satisfying than the existing ones that are offered by the competitors.
\end{abstract}

Keywords: Competitive Intelligence, Information gathering and sharing, Product Development and innovations, New products, New product offerings, Pharmaceutical firms.

\section{INTRODUCTION}

Competitive intelligence has remained a significant mediating variable for success in the business world today as its part of the strategies employed by organization for survival and expansion as organizations are experiencing increasing competition occasioned by globalization, glocalization, advanced technology, social economic variables and marketing dynamics. The marketing environment today has become

${ }^{1}$ Corresponding author: Department of Business Administration, Novena University, Kwale, Nigeria

${ }^{2}$ Department of Business Administration, Novena University, Kwale, Nigeria

${ }^{3}$ Department of Business Administration, Novena University, Kwale, Nigeria 
survival of the fittest and many struggled to survive to keep pace with the changing and dynamic environmental conditions. The need to know competitors and monitor their activities in the market place becomes imperative. To come to terms with this reality pharmaceutical firms are now focusing their strategies on product development and innovation. For a product to secure good position, market acceptance and a fair share of the market it must first find out the customer's needs, wants and expectations and develop product to meet their divergent requirements.

To achieve these objectives pertinent and actionable information must be available to empower organizations in information gathering and sharing. Competitive intelligence equips organization with the necessary information and knowledge needed for product development and innovation in the current information age in which knowledge is power (Haag and Cummings 2009). It is most pardonable to be beaten by competition but abhorrent to be taken by surprise, therefore it is most important to take proactive actions to identify the early warning signals as they occur in the market. For organization to survive and remain in the competitive aggressive and turbulent environment, the need for better and understanding and knowledge of the competitive forces that reshape the behavior of the environment cannot be over emphasized.

Karim (2011) agrees that knowledge is the main sources of product development and innovation, similarly, according to Ishikawa and Nakagawa (2013) those organizations that can understand their environment, their competitors and establish competitive management strategies will win in this rapidly globalized information society.

Therefore, having access to information and knowledge of the environment, and application of the intelligent information are essential element for organizational survival. According to Anica-Popa and Cucui (2009) competitive intelligence is the acquisition of and use of knowledge and information about competitors, customers, suppliers and support decision making process that will enhance competitiveness of the organization. The process of product development and innovation cannot be successful except there is information about customer's needs and requirements of which the innovated products or services intends to serve. Such information gathering and sharing no doubt will determine the nature of the new product and service so that the new product offerings will be more valued and satisfying than the existing ones that are provided by the competitors.

The strict regulations by government in the pharmaceutical industry today has become more critical for competitive intelligence as competitive intensity in the industry has increased due to technological complexities, products availability and variety and consumer sophistication. Therefore, for a pharmaceutical firm to improve on their performance and stand the test of time they must leverage on useful information gathered in their environment to engage not only in new product development and innovation but also constantly making relevant modifications to their existing product offerings to suit the market expectations and cope with the ever changing environment. This study shall examine the influence of competitive intelligence on product development and innovation in pharmaceutical firms in Lagos State, Nigeria.

\subsection{Statement of the Problem}

Industries these days are struggling for survival as a result of the stern competition occasioned by globalization, glocalization, advanced technology, socio-economic variables and other marketing dynamics. Instead of competitive intelligence to aid productivity and enhance performance as an intervening variable, reverse is the case, thus, 
creating a negative relationship among competing firms in the same industry, therefore managers of firms are compelled to adopt strategies that will enable them break away from the pack at all cost, hence indulge in clandestine industrial espionage.

Competitive intelligence ought to be a significant intervening variable for enhancing productivity, by its information gathering and sharing, analysis and interpretations and speculative consideration of future development patterns, risk and opportunities through the existence of human judgment.

Competitive intelligence is viewed as a process by the practitioners as it involves a set of legal and ethical methods for collecting, development, analyzing and disseminating actionable intelligence regarding competitors, suppliers, customers, the organization itself and business environment whose pressure has an underpinning with the improvement and performance of the organization to gain and sustain competitive advantage. For an organization to compete effectively in an environment that is in the state of flux, dynamic and changing nature and character, there is the need for inward and forward looking in terms of advance competitive opportunities, threats and industrial espionage and spy stuff as in the case of Nigeria Pharmaceutical industries.

Unhealthy competition has characterized Nigeria pharmaceutical industries as a result of industrial espionage, spy stuff, chronic hunger for target achievement, competitors profiling and information analysis either in the form of counterfeiting, swapping, re-coding of product eg. panadol, paracetamol, bonadol, etc also Aspirin, lisinoprin, vasoprin etc in the name of competitive intelligence.

These unethical and unhealthy competitive practices have been under serious attacks and condemnation occasioned by the fatalities accompanying the practice such that if not promptly checked could lead to loss of public legitimacy in the pharmaceutical industries and crisis in the health sectors as a whole.

Interestingly, a good number of measures have been put in place to reverse these negative trends to salvage the imminent crisis in the health sector. It is against this background that this research was conceived to proactively proffer effective strategies for solution to the looming danger in the competitive nature of competitive intelligence practice in the pharmaceutical sector in Lagos State.

\subsection{Objectives of the Study}

The broad objective of this study was to access and examine the nature of the relationship between competitive intelligence and product development and innovation in pharmaceutical firms while the specific objectives of the study are stated inter-alia:

1. To determine if competitive intelligence practice influences product development and innovations in Pharmaceutical firms.

2. To ascertain if competitive intelligence application has derived benefits.

3. To establish if pharmaceutical firms faces any challenge in applying competitive intelligence.

\subsection{Research Questions}

The under-listed research questions were raised in an attempt to achieve the objectives stated above.

1. How does competitive intelligence influence product development and innovation in Pharmaceutical firms?

2. What are the benefits derivable from competitive intelligence? 
3. In applying competitive intelligence, what are the challenges faced by pharmaceutical firms.

\section{THEORETICAL FRAMEWORK AND HYPOTHESES}

\subsection{Conceptual Review}

Competitive intelligence is yet another new concept in the field of management. It was the creation of porter five forces as a concept and new generated idea (Pellissier and Nenzhelele 2013). This concept made efforts to unravel some striking definitions and discussions as put forward by scholars and authors from different schools of thought. The society of competitive intelligence professionals, SCIP (2013) defined competitive intelligence as a systematic and ethical process for gathering, analyzing and managing external information that can affect the company's plans, decisions and operations. According to Colakoglu (2011) competitive intelligence means a systematic process initiated by organizations in order to gather and analyze information about competitors and the general socio-political and economic environment of the firm. The idea of this concept is to formulate a process of monitoring the competitive environment, with the sole aim of providing actionable intelligence that ensures competitive advantage to the organization (Kahaner 1997). The author also identified four objectives in relation to competitive intelligence, the first is to discover customers and competitors that are potentially new that can lend support to the environment of new business, secondly, the identification and analyses of new technologies product and process capable of influencing behavior and activities of the organization. Thirdly, identification and analyses of political and legal standards which acts as a regulation to influence behavior and activities of the organization and finally, identification and analysis of condition of competitors, suppliers among others that can translate into success or failure. In the opinion of McGonagle and Vella (2002) competitive intelligence was described as a formalized but developing process that is used by managers to evaluate the evolution of their industry and the capabilities and behavior of their competitors and those who might be their competitors in future. To support this assertion Teo and Choo (2001) assumed that competitive intelligence is the analytical process that transforms scattered information about competitors and customers into relevant, accurate and usable strategic knowledge on market evolution, business opportunities and threats. Karim (2011) stated that competitive intelligence is a systematic process that allows for identifying competitors plans and intentions to gain some advantages. The systematic process involves collecting, processing, analyzing, and distributing to top management and other decision makers any information about an organization's external environment. According to Blenkhorn and Fleisher (2005) competitive intelligence is a continuously evolving process that involves discovering, analyzing and using intelligence regarding competitors and general business environment from publicly available, non-proprietary information sources and converting it into knowledge on a continuing basis. Priporas et al. (2005) postulated that competitive intelligence can be considered as both a product and a process.

The product is data on the firm's competitors that is used as the foundation for action. The process is the methodical acquisition, analysis and evaluation of data for competitive advantage over known and potential competitors. Strategic decisions are made by executives through the help of these data that enable them to understand their competitors. Wheelen (2010) as cited in Charity and Joseph (2013) defined competitive intelligence as a formal program of gathering information on company's competitors. It 
is one of the fastest growing field within strategic management. Similarly, Rabaey et al. (2006) sees competitive intelligence as a structured judicious method and informing strategy and an innovation engine that draws better business outcome. To Haataja (2011)competitive intelligence is a strategic tool that helps enterprise to be aware of their competitors' behavior and plans. It produces actionable intelligence that in turn helps enterprises in decision making and good decision leads to higher achievements, hence competitive intelligence is being regarded as tool that helps enterprises to improve their performance (LI et al. 2011).

\subsection{Theoretical Review}

A good number of theories have been developed by scholars and authors from different schools of thought in order to buttress the authenticity of the subject matter. In this study the "open system theory" is adopted.

The theory was propounded by Ludwig von Bertanlanffy in 1956. Open system theory holds the view that organizations are strongly influenced by their internal and external environmental variables. The environment is made up of other actors that exert considerable and significant pressure such as political, socio-cultural, economic and technological, etc. and other internal environmental forces that influence the organization in different magnitudes. As these forces inter play in the environment, they possess boundaries that are visibly porous which permits interaction across the boundaries to enable new ideas and information infiltrations to bring about cross fertilization of viable ideas. In response to the above, organizations can adapt more quickly to the changes in the dynamic external environment where they operate. The interactions are a continuous flux among the sub-systems in the environment and are significant intervening variables for organizational survival and success.

Thus, any alert and proactive organization that are sensitive to the environment can survive, succeed and stand the test of time because of the organization's dependency on these inputs and service outputs.

Therefore, the aim of this theory is to explain how organization interact with their environment through competitive intelligence to gather data, information and knowledge about actors in the environment i.e. competitors, customers, suppliers, government etc in order to develop and innovate products and services to meet the needs, wants and expectations of the customers. Hence, open system theory identifies the concept of competitive intelligence as an ethical and legal business practice which seek to gather information from external business environment, turn them into actionable intelligence and utilizes it for the development and innovation of new products and services to meet the divergent needs, wants and expectations of the customers.

Figure 1. Interaction of Organizations with Environment through Competitive Intelligence New product development/redesigning existing products

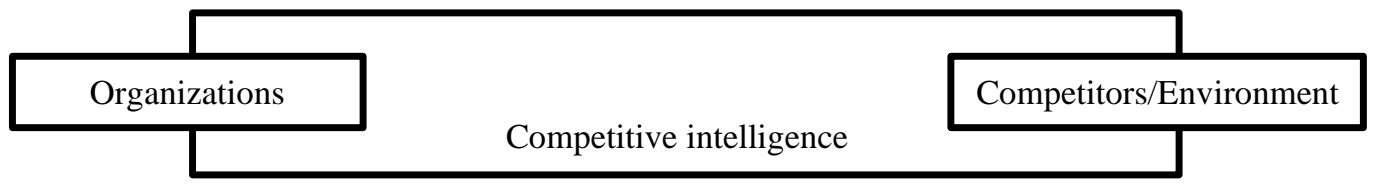

Source: Moneme and Nzewi (2017) Competitive Intelligence and Product Development in selected Pharmaceutical Firms in Anambra State, Nigeria 


\subsection{Empirical Review}

Nte et al. (2020) conducted a study on competitive intelligence and competitive advantage in pharmaceutical firms in developing economics: A review of Lagos State, Nigeria. The study examines the influence of competitive intelligence on competitive advantage of pharmaceutical firms in Lagos State, Nigeria. The study adopted survey research design; data were obtained from structured questionnaire and analyzed using the one sample t-test statistic. The study discovered among others that competitive intelligence is positively associated with the growth of the organization, higher quality and performance also that there are significant benefits derivable from competitive intelligence practice to guarantee product development and innovation in pharmaceutical firms. The study still discovered that there are significant challenges faced by pharmaceutical firms when applying competitive intelligence practice.

The study concluded that the role of competitive intelligence on competitive advantage is to provide strategic information that will guide pharmaceutical firms in the task of improved marketing innovations to meet the need of customers. The study recommended that for a pharmaceutical firm to gain competitive advantage and increase their performance they should leverage on useful information gathered in their environment to engage not only in product development but also constantly making relevant innovation and modifications to their existing marketing strategies.

Moneme and Nzewi (2017) carried out a study on competitive intelligence and product development in selected pharmaceutical firms in Anambra State, Nigeria. The study examines the influence of competitive intelligence on product development in selected pharmaceutical firms in Anambra State, Nigeria. Descriptive research design was adopted in this study; data were obtained from primary source and analyze using principal component analysis and multiple regression analysis. The study found that there is a significant relationship between competitive intelligence and product development in selected pharmaceutical firms in Anambra State, Nigeria.

The study concluded that the need to use competitive intelligence became imperative in the drive to seek for information in order to know the needs and want of the customer before developing products to meet the need and want of the customers. The study recommended that firms should place high premium on competitive intelligence if they must continue to be relevant to stand the test of time in the ever-changing market needs.

Afolabi et al. (2008) conducted empirical analysis on mobile phones users in Nigeria for competitive business intelligence; the main focus of the study was to evaluate the interestingness of a set of rules obtained from applying association rule mining algorithmic. The study discovered through questionnaire responses on phone brands and the number of users that Nokia phone products are the most widely used in Nigeria followed by Motorola, as a snapshot of the rules that were generated as a result of the application of association rule on the data.

In conclusion the study stated that the identification of user requirements and understanding the user is a major part of contributing to the profit of the organization and this can be achieved through competitive intelligence.

The empirical study by Charity and Joseph (2013) on "managing competitive intelligence for strategic advantage" it was found by the study that competitive intelligence is necessary because managers need it in their quest for increasing the quality of product and services, strategic planning and market knowledge; competitive intelligence is a veritable tool used for gathering information, converting the information 
into intelligence and utilizing the information in business decision making. It is the time money and intellectual skill that constitute the cost of competitive intelligence; this study showed also that there is a significant positive relationship existing between competitive intelligence and strategic advantage.

In the empirical study by Ain (2013) they examined the role of competitive intelligence in multinational companies and the performance of the organization as a competitive advantage. The study revealed that competitive intelligence is strongly associated with the growth of the organization, higher quality and performance of organization to attain a strong position in the market and to meet competencies against its competitors.

The research work by Nwokah and Ondukwu (2009) on competitive intelligence and marketing effectiveness in corporate organization in Nigeria. It was recorded by the study that there is a strong association between competitive intelligence and marketing effectiveness in corporate organizations in Nigeria. Also in the study it was observed that competitive intelligence leads to marketing effectiveness in corporate organizations in Nigeria.

The study concluded that knowledge concerning the impact of competitive intelligence and marketing effectiveness of corporate organization in Nigeria was significantly refined by the study. In recommendation the study reported that management should employ adequate measures to consistently motivate its intelligence team so as to be able to proactively analyze customer's need and fashion out strategies to satisfy these needs.

\subsection{Research Hypotheses}

The following null hypotheses were formulated for the study.

$\mathrm{Ho}_{1}$ : Competitive intelligence does not significantly influence product development and innovation in pharmaceutical firms.

$\mathrm{Ho}_{2}$ : There are no significant benefits derivable from competitive intelligence practice to guarantee product development and innovation in Pharmaceutical firms

Ho3: There are no significant challenges faced by Pharmaceutical firms when applying competitive intelligence practice.

\section{RESEARCH METHOD}

The design of this study was based on survey research; this research design seems the best for this study since the intent was to establish whether or not a relationship existed between two variables i.e. competitive intelligence and product development and innovation.

\subsection{Population of the Study}

There are fifty-six (56) Pharmaceutical Companies in Lagos State (Pharma approach.com 2017) based on Tabel 1 (Appendix). So, the population of the study consists of all the pharmaceutical companies in the state. The list of the companies are shown in Table 2 (Appendix).

\subsection{Sampling and Sampling Techniques}

The researcher adopted combination of disproportionate stratified and random sampling techniques. The disproportionate stratified technique was chosen because of the different areas and uneven distribution of the firms. So, in order to make every part of 
Lagos State be part of the study, the stratified technique was adopted and because the companies are not evenly distributed, the researcher was disproportionate in choosing the companies. Also, the random technique was adopted in selecting the companies and the respondents for the study.

\subsection{Sampling Size Determination}

For the purpose of this study, the sample size is one hundred and ninety-five (195) respondents.

Table 2. List of Pharmaceutical companies in Lagos State

\begin{tabular}{|c|c|c|c|c|c|}
\hline $\mathbf{S} / \mathbf{N}$ & Area & $\begin{array}{c}\text { Number of } \\
\text { Pharmaceutical } \\
\text { Companies }\end{array}$ & $\begin{array}{c}\text { Number of Firms } \\
\text { Selected } \\
\text { (Randomly) }\end{array}$ & Company Selected & $\begin{array}{c}\begin{array}{c}\text { Staff/respond } \\
\text { ents Selected } \\
\text { (Randomly) }\end{array} \\
\end{array}$ \\
\hline 1 & Ikeja & 25 & 1 & BCN plc & 15 \\
\hline 2 & Isolo & 8 & 1 & $\begin{array}{l}\text { Afrab-Chem } \\
\text { Limited } \\
\text { Mopson }\end{array}$ & 15 \\
\hline 3 & Yaba & 2 & 1 & $\begin{array}{l}\text { Pharmaceuticals } \\
\text { limited }\end{array}$ & 15 \\
\hline 4 & Ikorodu & 1 & 1 & $\begin{array}{l}\text { Biopharma Nigeria } \\
\text { Ltd }\end{array}$ & 15 \\
\hline 5 & Mushin & 2 & 1 & $\begin{array}{l}\text { Bond Chemical } \\
\text { industries ltd }\end{array}$ & 15 \\
\hline 6 & Agege & 3 & $\begin{array}{l}\text { Orfema } \\
\text { Pharmaceutical } \\
\text { Industries Limited }\end{array}$ & (1) & 15 \\
\hline 7 & Okota & 1 & 1 & Clatess Limited & 15 \\
\hline 8 & Oshodi & 3 & 1 & $\begin{array}{l}\text { Daily-Need } \\
\text { Industries }\end{array}$ & 15 \\
\hline 9 & Ijesha & 1 & 1 & $\begin{array}{l}\text { Dana Drugs } \\
\text { Limited }\end{array}$ & 15 \\
\hline 10 & Igando & 1 & $\begin{array}{l}\text { Divine Essential } \\
\text { Formulations }\end{array}$ & 12 & 15 \\
\hline 11 & $\begin{array}{l}\text { VI/Amuwo } \\
\text { Odofin }\end{array}$ & 3 & 1 & $\begin{array}{l}\text { Geneith } \\
\text { Pharmaceuticals } \\
\text { limited }\end{array}$ & 15 \\
\hline 12 & Badagary & 3 & 1 & $\begin{array}{l}\text { New Heathway } \\
\text { Pharmaceuticals } \\
\text { limited } \\
\text { Oak-Faith }\end{array}$ & 15 \\
\hline 13 & Ojota/Ketu & 3 & 1 & $\begin{array}{l}\text { Pharmaceutical } \\
\text { Resource limited }\end{array}$ & 15 \\
\hline & Total & 56 & 13 & 24 & 195 \\
\hline
\end{tabular}

Sources: Researchers Compilation 2020

Because of the uneven distribution of the companies in the thirteen areas where the companies are located, and locations of the firms, Lagos State is stratified into thirteen strata (table 1) and the researcher disproportionately select one (1) company each from each of the thirteen strata (area) where the companies are located. This makes it a total of thirteen (13) pharmaceutical companies selected for the study. Where the companies are more than one the researcher used the random sampling technique to choose one. From each company selected for the study, fifteen (15) staff (respondents) were randomly selected (five management staff, five senior staff and five junior staff). Multiplying the thirteen areas where the companies are located by fifteen staff randomly selected from 
each company makes it a total of one hundred and ninety-five (195) respondents for the study. (See table 2).

\subsection{Research Instrument}

The instruments used for collection of data are structural questionnaire designed by the researcher. The questionnaire has two parts, Part A and Part B, all the questions in Part A provide general information about the respondents while the questions in Part B address the research questions, five-point Likert scale format was used. The questionnaire contains a total of 40 questions.

\subsection{Validity of the Instrument}

In this study when the questionnaire was drafted, it was submitted to five experts in the field for their scrutiny, comments and criticisms. This was imperative so as to ensure that no important variables were left out. The comments, recommendations and useful suggestions were considered in making the final draft.

\subsection{Reliability of the Instrument}

In testing for the reliability of the study, two pharmaceutical firms in Lagos State were chosen and thirty staff was selected from the two firms. The Cronbach's alpha was used to test for the reliability of the study. The result of the Cronbach's alpha coefficient of the variables was $83 \%$ reliable. This implies that the instrument is reliable.

\subsection{Method of Data Collection}

The method used in the collection of data in this study is questionnaire. The primary data used for this study were gathered through questionnaire. A structured questionnaire was used in gathering relevant data with options provided for respondents on a five-point Likert scale. Response to the items ranges from (5-Strongly Agree (SA), (4-Agree (A), (3-Disagree (D), (2- Strongly Disagree (SD) to (1-undecided) (u)

\subsection{Method of Data Analysis}

The stated research hypotheses were analyzed using the Pearson's ProductMoment Coefficient of Correlation in order to test whether the independent variable (competitive intelligence) affect the dependent variable product development and innovation. Decision was established based on the results. Decision was established based on rejection or acceptance of null hypotheses, if the calculated value exceeds the critical value (3.182), reject the null hypothesis, otherwise the alternative hypothesis will be upheld. Or, if the t-value is less than the alpha level (0.05) reject the null hypothesis, otherwise accept. The hypotheses were tested at $95 \%$ level of confidence.

\subsection{Decision Rule}

In testing hypotheses, calculated value of the test statistic was compared with critical or table value of the statistic. The critical or table value serves as a benchmark for rejecting or not rejecting the null hypotheses. Therefore, the decision rule applied in this study is to reject the null hypotheses if the calculated value is greater than the critical table at $95 \%$ (3.182) confidence level, otherwise reject the null hypotheses. Or reject the null hypotheses if the t-value is less than the critical value of 0.05 , otherwise accept the null hypotheses. 


\section{RESULT AND DISCUSSION}

In the study of competitive intelligence and product development and innovation in pharmaceutical companies. In carrying out the study, the researcher used primary source of data collection through questionnaire designed by the researcher. A total of one hundred and ninety-five (195) questionnaires were distributed and after careful monitoring and supervision, one hundred and fifty was retrieved back. This shows $77 \%$ response rate or $77 \%$ interest in the study by the respondents. In analyzing the personal data simple percentage was use while in the research questions and hypotheses, the Pearson's Product Moment Coefficient of Correlation is used.

\subsection{Analysis of Personal Data}

Table 3. Position of Respondents

\begin{tabular}{|l|c|c|}
\hline Position & Frequency & Percent \\
\hline Junior & 70 & 47 \\
Senior & 30 & 20 \\
Management & 50 & 33 \\
\hline Total & $\mathbf{1 5 0}$ & $\mathbf{1 0 0}$ \\
\hline
\end{tabular}

Source: Researchers' field survey 2020.

The result of table 3 indicates that there are more junior staff in the study with a statistic of $47 \%$. A breakdown of the result shows that junior staff has $47 \%$, senior staff has $30.2 \%$ and management staff has $33 \%$.

Table 4. Sex of Respondents

\begin{tabular}{|l|c|c|}
\hline Sex & Frequency & Percent \\
\hline Female & 50 & 33 \\
Male & 100 & 67 \\
\hline Total & $\mathbf{1 5 0}$ & $\mathbf{1 0 0}$ \\
\hline
\end{tabular}

Source: Researchers' field survey 2020.

The result of table 4 indicates that there are more male staff in the study with a statistic of $67 \%$. A breakdown of the result shows that male staff has $67 \%$, while female staff has $33 \%$.

Table 5. Educational Qualification of Respondents

\begin{tabular}{|l|c|c|}
\hline Educational Qualification & Frequency & Percent \\
\hline SSCE & 40 & 27 \\
OND/NCE & 60 & 40 \\
HND/B.Sc. & 30 & 20 \\
M.Sc./MBA/PHD & 20 & 13 \\
\hline Total & $\mathbf{1 5 0}$ & $\mathbf{1 0 0}$ \\
\hline
\end{tabular}

Source: Researchers' field survey 2020.

The result of table 5 indicates that most of the respondents in the study have OND/NCE with $40 \%$. A breakdown of the result shows that respondents with SSCE has $27 \%$, $\mathrm{OND} / \mathrm{NCE}$ has $40 \%$, first degree is $20 \%$ and above first degree is $13 \%$. 
Table 6. Work Experience of Respondents

\begin{tabular}{|l|c|c|}
\hline Work experience & Frequency & Percent \\
\hline Less than 5 & 28 & 18 \\
5-9 years & 57 & 38 \\
10-14 years & 43 & 29 \\
Above 14 years & 22 & 15 \\
\hline Total & $\mathbf{1 5 0}$ & $\mathbf{1 0 0}$ \\
\hline
\end{tabular}

Source: Researchers' field survey 2020.

The result of table 6 indicates that most of the respondents in the study have between 5-9 years' work experience with 38\%. A breakdown of the result shows that respondents with less than five years' experience has 18\%, 5-9 years has 38\%, 10-14 years has $29 \%$ and above 14years working experience has $15 \%$.

Table 7. Respondents View on The Influence of Product Development and Innovation in Pharmaceutical Firms by Competitive Intelligence

\begin{tabular}{|c|l|c|c|}
\hline S/N & Options & Frequency & Percentage \\
\hline 1. & Strongly Agree & 60 & 40 \\
2. & Agree & 40 & 27 \\
3. & Disagree & 25 & 17 \\
4. & Strongly Disagree & 20 & 13 \\
5. & Undecided & 5 & 3 \\
\hline & TOTAL & $\mathbf{1 5 0}$ & $\mathbf{1 0 0}$ \\
\hline
\end{tabular}

Source: Researcher's field survey 2020

The table above shows that $60(28 \%)$ of the respondents strongly agreed that product development and innovation have a significant influence on pharmaceutical firms by competitive intelligence, 40 (27\%) agreed, 25 (17\%) disagreed, 20 (13\%) strongly disagreed and $5(3 \%)$ undecided.

Table 8. Respondents Opinion on The Benefits Derivable from Competitive Intelligence to Guarantee Product Development and Innovation in Pharmaceutical Firms

\begin{tabular}{|c|l|c|c|}
\hline S/N & Options & Frequency & Percentage \\
\hline 1. & Strongly Agree & 65 & 44 \\
2. & Agree & 35 & 23 \\
3. & Disagree & 25 & 17 \\
4. & Strongly Disagree & 20 & 13 \\
5. & Undecided & 5 & 3 \\
\hline & TOTAL & $\mathbf{1 5 0}$ & $\mathbf{1 0 0}$ \\
\hline
\end{tabular}

Source: Researcher's field survey 2020

The above table revealed that $65(44 \%)$ of the respondents strongly agreed that there are benefit derivable from competitive intelligence to guarantee product development and innovation in pharmaceutical firms, 35 (23\%) agreed, 25 (17\%) disagreed, 20 (13\%) strongly disagreed and 5 (3\%) undecided. 
Table 9. Respondents View on The Challenges Faced by Pharmaceutical Firms When Applying Competitive Intelligence Practice

\begin{tabular}{|c|l|c|c|}
\hline S/N & Options & Frequency & Percentage \\
\hline 1. & Strongly Agree & 62 & 42 \\
2. & Agree & 38 & 25 \\
3. & Disagree & 25 & 17 \\
4. & Strongly Disagree & 20 & 13 \\
5. & Undecided & 5 & 3 \\
\hline & TOTAL & $\mathbf{1 5 0}$ & $\mathbf{1 0 0}$ \\
\hline
\end{tabular}

Source: Researcher's field survey 2020

The table above shows that $62(42 \%)$ of the respondents strongly agreed that there are challenges faced by pharmaceutical firms when applying competitive intelligence practice, $38(25 \%)$ agreed, $25(17 \%)$ disagreed, 20 (13\%) strongly disagreed and $5(3 \%)$ undecided.

\subsection{Test of Hypotheses}

To ascertain the validity and reliability of the research outcome, the hypotheses are tested using the Pearson's product-moment coefficient of correlation.

\subsubsection{Test of Hypotheses One}

Ho1: Competitive Intelligence does not significantly influence product development and innovation in pharmaceutical firms.

Table 10. Respondents View on The Influence of Product Development and Innovation in Pharmaceutical Firms by Competitive Intelligence

\begin{tabular}{|c|l|c|c|}
\hline S/N & Options & Frequency & Percentage \\
\hline 1. & Strongly Agree & 60 & 40 \\
2. & Agree & 40 & 27 \\
3. & Disagree & 25 & 17 \\
4. & Strongly Disagree & 20 & 13 \\
5. & Undecided & 5 & 3 \\
\hline & TOTAL & $\mathbf{1 5 0}$ & $\mathbf{1 0 0}$ \\
\hline
\end{tabular}

Source: Table 7

Table 11. Contingency Table

\begin{tabular}{|c|c|c|c|c|}
\hline $\mathbf{X}$ & $\mathbf{Y}$ & $\mathbf{X}^{\mathbf{2}}$ & $\mathbf{Y}^{\mathbf{2}}$ & $\mathbf{X Y}$ \\
\hline 5 & 60 & 25 & 3600 & 300 \\
4 & 40 & 16 & 1600 & 160 \\
3 & 25 & 9 & 625 & 75 \\
2 & 20 & 4 & 400 & 40 \\
1 & 5 & 1 & 25 & 5 \\
\hline $\mathbf{1 5}$ & $\mathbf{1 5 0}$ & $\mathbf{5 5}$ & $\mathbf{6 2 5 0}$ & $\mathbf{5 8 0}$ \\
\hline
\end{tabular}

Source: Researcher's computation, 2020 
Figure 2. Computation of Hypotheses One

$$
\begin{aligned}
r & =\frac{n \sum x y-\left(\sum x\right)\left(\sum y\right)}{\sqrt{\left.\left[n \sum x^{2}-\left(\sum x\right)^{2}\right]\left[n \sum y^{2}\right)-\left(\sum y\right)^{2}\right]}} \\
& =\frac{5(580)-15(150)}{\sqrt{[5(55)-15 \times 15][5 \times 6250-150 \times 150]}} \\
& =\frac{2.900-2.250}{\sqrt{[275-225][31.250-22.500]}} \\
& =\frac{650}{437.500} \\
r & =0,98
\end{aligned}
$$

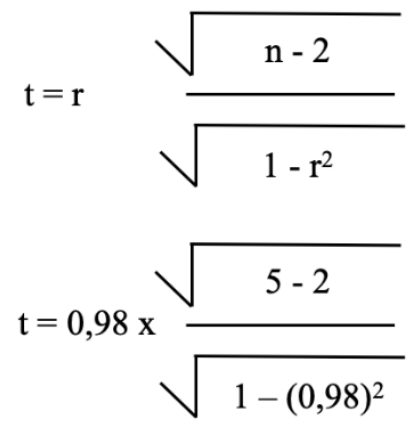

$t=0,98 \times \quad \frac{1,73}{0,2}$

$\mathrm{t}=0,98 \times 8,65$

$\mathrm{t}=8,5$

Table value $=3,182$

Source: Researcher's computation, 2020

From the above calculated value 8.5 in Figure 2. (Appendix), when compared with table value $\mathrm{t}=3.182$, at $5 \%$ level of significance, the null hypothesis is rejected, while the alternative hypothesis is accepted and conclude that there is a significant influence of competitive intelligence on product development and innovation.

\subsubsection{Test of Hypothesis Two}

Ho2: There are no significant benefits derivable from competitive intelligence practice to guarantee product development and innovation in pharmaceutical firms.

Table 12. Respondents Opinion on The Benefits Derivable from Competitive Intelligence to Guarantee Product Development and Innovation in Pharmaceutical Firms

\begin{tabular}{|c|l|c|c|}
\hline S/N & Options & Frequency & Percentage \\
\hline 1. & Strongly Agree & 65 & 44 \\
2. & Agree & 35 & 23 \\
3. & Disagree & 25 & 17 \\
4. & Strongly Disagree & 20 & 13 \\
5. & Undecided & 5 & 3 \\
\hline & TOTAL & $\mathbf{1 5 0}$ & $\mathbf{1 0 0}$ \\
\hline
\end{tabular}

Source: Table 8 
Table 13: Contingency Table

\begin{tabular}{|c|c|c|c|c|}
\hline $\mathbf{X}$ & $\mathbf{Y}$ & $\mathbf{X}^{\mathbf{2}}$ & $\mathbf{Y}^{\mathbf{2}}$ & $\mathbf{X Y}$ \\
\hline 5 & 65 & 25 & 4225 & 325 \\
4 & 35 & 16 & 1225 & 140 \\
3 & 25 & 9 & 625 & 75 \\
2 & 20 & 4 & 400 & 40 \\
1 & 5 & 1 & 25 & 5 \\
\hline $\mathbf{1 5}$ & $\mathbf{1 5 0}$ & $\mathbf{5 5}$ & $\mathbf{6 5 0 0}$ & $\mathbf{5 8 5}$ \\
\hline
\end{tabular}

Source: Researcher's computation, 2020

Figure 3. Computation of Hypotheses Two

$$
\begin{aligned}
r & =\frac{n \sum x y-\left(\sum x\right)\left(\sum y\right)}{\sqrt{\left.\left[n \sum x^{2}-\left(\sum x\right)^{2}\right]\left[n \sum y^{2}\right)-\left(\sum y\right)^{2}\right]}} \\
& =\frac{5(585)-15(150)}{\sqrt{[5(55)-15 \times 15][5 \times 6500-150 \times 150]}} \\
& =\sqrt{\frac{[275-225][32.500-22.500]}{675}} \\
& =\sqrt{\frac{500.000}{6}}
\end{aligned}
$$

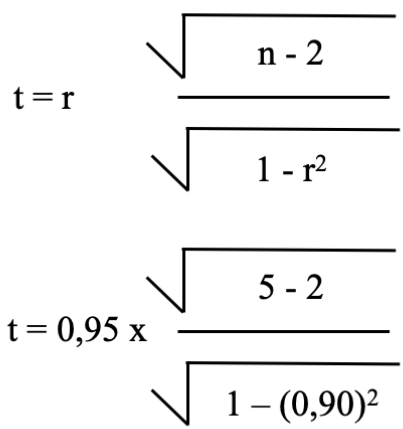

$\mathrm{t}=0,95 \times \frac{1,73}{0,43}$

$t=0,95 \times 4,02$

$\mathrm{t}=3,819$

Table value $=3,182$

Source: Researcher's computation, 2020

From the above calculated value 3.819 , when compared with table value $\mathrm{t}=3.182$, at $5 \%$ level of significance, the null hypothesis is rejected while the alternative hypothesis is accepted and conclude that there are benefits derivable from competitive intelligence practice to guarantee product development and innovation in pharmaceutical firms.

\subsubsection{Test of Hypotheses Three}

Ho1: There are no significant challenges faced by pharmaceutical firms when applying competitive intelligence practice.

Table 14. Respondents View on The Challenges Faced by Pharmaceutical Firms

When Applying Competitive Intelligence Practice

\begin{tabular}{|c|l|c|c|}
\hline S/N & Options & Frequency & Percentage \\
\hline 1. & Strongly Agree & 62 & 42 \\
2. & Agree & 38 & 25 \\
3. & Disagree & 25 & 17 \\
4. & Strongly Disagree & 20 & 13 \\
5. & Undecided & 5 & 3 \\
\hline & TOTAL & $\mathbf{1 5 0}$ & $\mathbf{1 0 0}$ \\
\hline
\end{tabular}

Source: Table 9 
Table 15. Contingency Table

\begin{tabular}{|c|c|c|c|c|}
\hline $\mathbf{X}$ & $\mathbf{Y}$ & $\mathbf{X}^{\mathbf{2}}$ & $\mathbf{Y}^{\mathbf{2}}$ & $\mathbf{X Y}$ \\
\hline 5 & 62 & 25 & 3844 & 310 \\
4 & 38 & 16 & 1444 & 152 \\
3 & 25 & 9 & 625 & 75 \\
2 & 20 & 4 & 400 & 40 \\
1 & 5 & 1 & 25 & 5 \\
\hline $\mathbf{1 5}$ & $\mathbf{1 5 0}$ & $\mathbf{5 5}$ & $\mathbf{6 3 3 8}$ & $\mathbf{5 8 2}$ \\
\hline
\end{tabular}

Source: Researcher's computation, 2020

Figure 4. Computation of Hypotheses Three
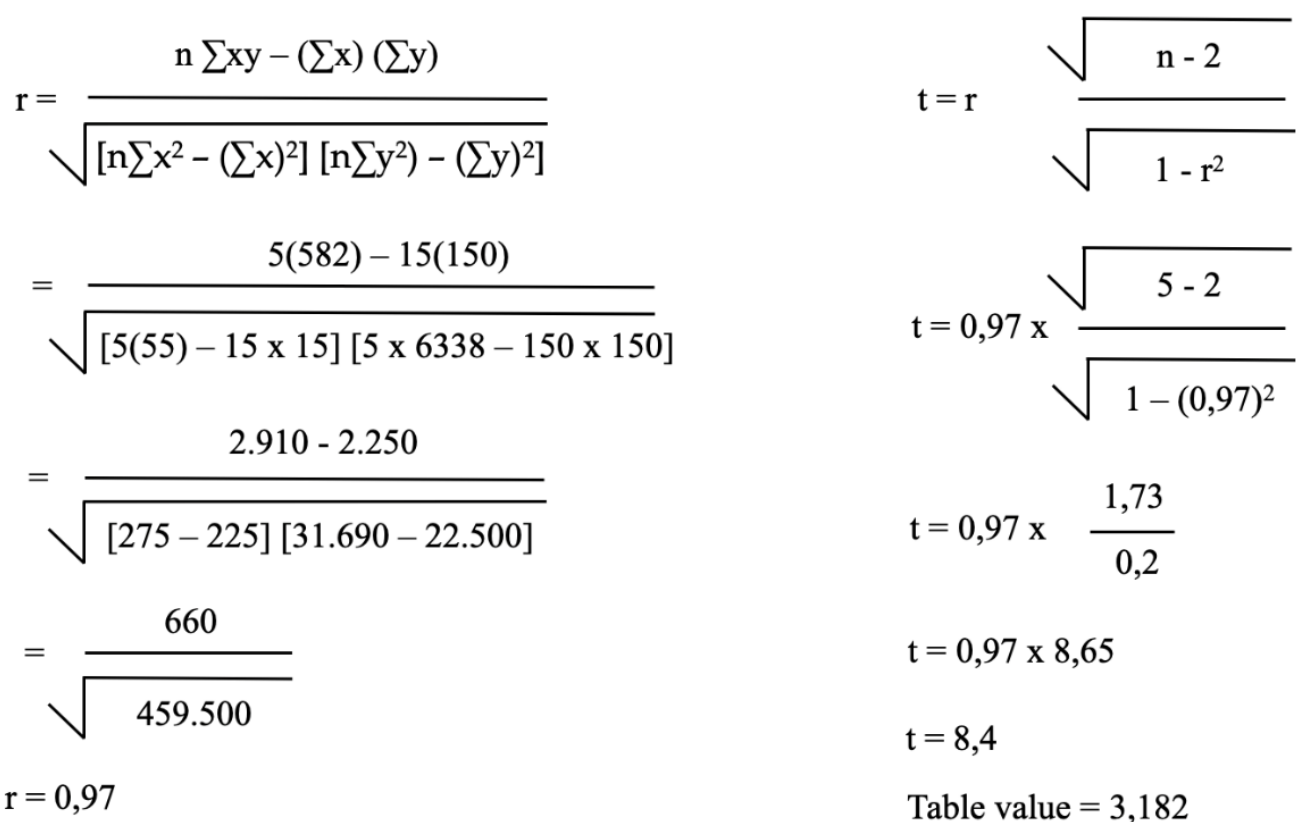$$
\mathrm{t}=0,97 \times \frac{1,73}{0,2}
$$$$
t=0,97 \times 8,65
$$$$
\mathrm{t}=8,4
$$

Table value $=3,182$

Source: Researcher's computation, 2020

From the above calculated value 8.4, when compared with table value $t=3.182$, at $5 \%$ level of significance, the null hypothesis is rejected, while the alternative hypothesis is accepted and conclude that there are challenges faced by pharmaceutical firms when applying competitive intelligence practice.

\subsection{Discussion}

This study examined the influence of competitive intelligence on product development and innovation in pharmaceutical firms in Lagos state, Nigeria. The finding of hypotheses one revealed that there is a significant influence of competitive intelligence on product development and innovation in pharmaceutical firm in Lagos State, this is in line with the views of Nte et al. (2020) who discovered that competitive intelligence is positively associate with the growth of organization, higher quality and performance. In the same line of thinking, Moneme and Nzewi (2017) in their study competitive intelligence and product development of selected pharmaceutical firms in Anambra State, Nigeria that there is a significant relationship existing between competitive intelligence and product development. 
The result of hypotheses two revealed that there is a significant benefits derivable from competitive intelligence practice to guarantee product development and innovation in pharmaceutical firms, this is in alignment with the views of Charity and Joseph (2013) in their study managing competitive intelligence for strategic advantage, it revealed that competitive intelligence is necessary because managers need it in their quest for increasing the quality of product and services, strategic planning and market knowledge. The authors further stated that competitive intelligence is a significant intervening variable on competitive advantage in the business world as part of survival and expansion. In the same vein, Haag and Cummings (2009) stated that competitive intelligence equips organizations with the necessary information and knowledge needed for product development and innovation in the current information age in which knowledge is power.

Hypotheses three revealed that there are significant challenges faced by pharmaceutical firms when applying competitive intelligence practice. This agrees with the opinion of Nte et al. (2020) who stated that industries are struggling to survive as a result of stiff competition created by globalization, glocalization, advance technology, socio-economic variables and marketing dynamics. The authors further stressed that pharmaceutical firms are enmeshed in a lot of unhealthy medical conundrum as a result of industrial espionage, spy stuff, monitoring direct competitors' behavior and analysis of competitor information in form of counterfeiting, swapping, re-coding of products eg. panadol, bonadol, paracemol, aspirin, vasoprin, lisinoprin etc in the name of competitive intelligence. In alignment with the above, Anica-Popa and Cucui (2009) emphasized the need for information gathering and sharing, it was stated that the process of product development and innovation cannot be successful except there is information about customers' needs and requirements of which the innovated products or services intends to serve. The authors noted that such information gathering and sharing no doubt will determine the nature of the new product and service so that the new product offerings will be more valued and satisfying than the existing ones that are provided by the competitor.

Another challenge experienced by the pharmaceutical firms in support of the finding of hypotheses three is strict regulation of the pharmaceutical industry by government and her agencies. According to Moneme and Nzewi (2017) the strict regulation by government in pharmaceutical industry today has become more critical for competitive intelligence as competitive intensity in the industry has increased due to technological complexities, product availability and variety and consumer sophistication. Therefore, for a pharmaceutical firm to improve on their performance and stand the test of time they must leverage on useful information gathered from their environment to engage not only in new product development and innovations but also to constantly making relevant modifications to their existing product offerings to suit the market expectations and cope with ever changing environment.

\section{CONCLUSION AND SUGGESTION \\ 5.1 Conclusion}

Competitive intelligence has remained a significant mediating variable on product development and innovation in the business world today as part of survival and expansion, therefore, the need for competitive intelligence in product development and innovation cannot be over emphasized. This study examined the influence of competitive intelligence on product development and innovation in pharmaceutical firms in Lagos state. The result of the findings revealed among others that competitive intelligence significantly influences product development and innovation in pharmaceutical firms. 
This is because information gathering and sharing by pharmaceutical firms determines the nature of the new product and service so that the new product offerings will be more valued and satisfying than the existing ones that are provided by the competitors.

The process of product development and innovation cannot be successful except there is information about customers' needs, wants and expectations of which the innovated product or service intends to serve. The study concluded that for a pharmaceutical firm to improve on their performance and stand the test of time they must leverage on useful information gathered in their environment to engage not only in new product development and innovation but also constantly making relevant modifications to their existing product offerings to suit the market expectations, wants and needs and cope with the ever changing and dynamic environment.

\subsection{Recommendations}

The following policy recommendations are advanced for the study.

1. The government should expand the scope of her regulation / measures to ameliorate the high level of industrial espionage, spy stuff, counterfeiting, re-coding of product etc. in the name of competitive intelligence in order to reverse the looming negative trends in the pharmaceutical firms.

2. The pharmaceutical firms should expand and strengthen their information gathering and sharing mechanisms in their environment to engage not only in new product development and innovation but also continually making relevant modifications to their existing product offerings to suit the market expectation and cope with the everchanging environmental conditions.

\section{REFERENCES}

Afolabi, I., C. Uwadia, and C. K. Ayo. 2008. An Empirical Analysis of Mobile Phone Users for Competitive Business Intelligence. i-manager's Journal on Management 3 (2):70-75.

Ain, N. U. 2013. Role of competitive intelligence in multinational companies. International Journal of Emerging Sciences 3 (2): 171.

Anica-Popa, I., and G. Cucui. 2009. A framework for enhancing competitive intelligence capabilities using decision support system based on web mining techniques. International Journal of Computers Communications \& Control 4 (4):326-334.

Blenkhorn, D. L., and C. S. Fleisher. 2005. Competitive intelligence and global business: Greenwood Publishing Group.

Charity, A. E., and I. U. Joseph. 2013. Manage competitive intelligence for strategic advantage. European Journal of Business and Management 5 (3):1-9.

Colakoglu, T. 2011. The Problematic Of Competitive Intelligence: How To Evaluate\& Develop Competitive Intelligence? Procedia-Social and Behavioral Sciences 24:1615-1623.

Haag, S., and M. Cummings. 2009. Management information systems for the information age: McGraw-Hill, Inc.

Haataja, J.-E. 2011. Social media as a source of competitive intelligence in a pharmaceutical corporation. 
Ishikawa, A., and J. Nakagawa. 2013. An Introduction to Knowledge Information Strategy: From Business Intelligence to Knowledge Sciences: World Scientific Publishing Company.

Kahaner, L. 1997. Competitive intelligence: how to gather analyze and use information to move your business to the top: Simon and Schuster.

Karim, A. J. 2011. The value of competitive business intelligence system (CBIS) to stimulate competitiveness in global market. International Journal of Business and Social Science 2 (19).

LI, W.-s., M. SHI, and X.-k. XIAO. 2011. Research on industrial competitive intelligence and technology life cycle based on the patent analysis_- taking the thin film solar cells industry as example [J]. Technological Development of Enterprise 11.

McGonagle, J. J., and C. M. Vella. 2002. A case for competitive intelligence. Information Management 36 (4):35.

Moneme, C. P., and H. N. P. Nzewi. COMPETITIVE INTELLIGENCE AND PRODUCT DEVELOPMENT IN SELECTED PHARMACEUTICAL FIRMS IN ANAMBRA STATE OF NIGERIA.

Nte, N. D., K. N. Omede, B. K. Enokie, and O. Bienose. Competitive Intelligence and Competitive Advantage in Pharmaceutical Firms in Developing Economies: A Review of Lagos State, Nigeria.

Nwokah, N. G., and F. Ondukwu. 2009. Competitive intelligence and marketing effectiveness in corporate organizations in Nigeria. African Journal of Marketing Management 1 (1):010-022.

Pellissier, R., and T. E. Nenzhelele. 2013. Towards a universal definition of competitive intelligence. South African Journal of Information Management 15 (2):1-7.

Priporas, C. V., L. Gatsoris, and V. Zacharis. 2005. Competitive intelligence activity: evidence from Greece. Marketing Intelligence \& Planning.

Rabaey, M., J.-M. Leclercq Jr, E. Vandijck, G. Hoffman, and M. Timmerman. 2006. Intelligence base: Strategic instrument of an organisation: VRIJE UNIV BRUSSELS (BELGIUM).

SCIP, U. 2013. Society of Competitive Intelligence Professionals: USA.

Teo, T. S., and W. Y. Choo. 2001. Assessing the impact of using the Internet for competitive intelligence. Information \& management 39 (1):67-83.

Wheelen, T. L. 2010. Strategic Management and Business Policy: Mymanagementlab Student Access Code Card: Prentice Hall. 
APPENDIX

Table 1. Location of Pharmaceutical Companies in Lagos State

\begin{tabular}{|c|c|c|}
\hline S/N & Area & Number of Pharmaceutical Companies \\
\hline 1. & Ikeja & 25 \\
2. & Isolo & 8 \\
3. & Yaba & 2 \\
4. & Ikorodu & 1 \\
5. & Mushin & 2 \\
6. & Agege & 3 \\
7. & Okota & 1 \\
8. & Oshodi & 3 \\
9. & Ijesha & 1 \\
10. & Igando & 1 \\
11. & Vitoria Island & 3 \\
12. & Badagary & 3 \\
13. & Ojota/Ketu & 3 \\
\hline & Total & $\mathbf{5 6}$ \\
\hline
\end{tabular}

Sources: Pharmaapproach.com, 2017 and Researchers Compilation 2020. 